\title{
Familial spastic paraplegia with amyotrophy of the hands
}

\author{
J. R. SILVER ${ }^{1}$ \\ From the Department of Neurology, the Middlesex Hospital, London
}

\section{4}

Familial spastic paraplegia is not a common condition; it is believed to be a genetically determined neurological disorder, although its exact mode of inheritance and its relationship to other disorders of the nervous system are still in dispute.

The usual manifestations of familial spastic paraplegia are stiffness and weakness in the lower limbs leading to difficulty in walking, the usual complaint being catching the toes on the ground and stumbling. It may present at any age, but usually appears in childhood or early adult life. It is a relatively benign condition. The lower limbs are weak and spastic, with increased tendon reflexes and usually extensor plantar responses, while in most cases there are no other abnormalities. Additional features have been described, such as mental defect, optic atrophy, nystagmus, cataract, dysarthria, cerebellar deficits, kyphosis, pes cavus, and occasionally wasting of the legs, shoulders, or hands.

Wasting is not a common feature of this disorder, having been observed in only one or two members of an affected family. It is usually delayed in onset, appearing when spasticity has been established for many years. It has been difficult to account for this wasting and it has been suggested that it is a disuse atrophy in the weak spastic muscles. The cases presented here suggest that it is a specific genetic phenomenon in its own right.

Two families are described, in which wasting of the hands was the first and most marked manifestation. None of the affected individuals complained of weakness in the legs, though examination revealed a pyramidal disturbance. The disorder is inherited on a dominant basis and appears to be a variety of familial spastic paraplegia.

Adolf Strümpell was the first to give a full clinical and pathological description of familial spastic paraplegia. In a series of papers between 1880 and 1904 he described two separate families, the Gaums and the Polsters, whom he looked after at the Erlangen Clinic. Since that time papers have been published by Philip (1886), Gee (1889), Tooth (1891), Newmark (1893), Ormerod (1904), Holmes (1905), Jones (1907), Ogilvie (1908), Punton (1909), Rhein

1 Present address: Promenade Hospital, Southport.
(1916), Williams (1918), Mason and Rienhoff (1920), Manson (1920), Ferguson and Macdonald Critchley (1929), Paskind and Stone (1933), Worster-Drought, Hill, and McMenemey (1933), Worster Drought, Greenfield, and McMenemy (1940 and 1944), Bell and Carmichael (1939), Sjögren (1943), Garland and Astley (1950), Bickerstaff (1950), Schut (1950, 1951, and 1954), Matson, Schut, and Swanson (1961) Landau and Gitt (1951), Schwartz (1952), Dick and Stevenson (1953), Refsum and Skillicorn (1954), Tyrer and Sutherland (1961), and Roe (1963). These have all added fresh families to the literature, the fullest review of the clinical and genetic features being by Bell and Carmichael (1939) and the most comprehensive pathological account by Schwartz (1952). The only families which regularly showed wasting of the hands as part of the disorder were those described by Gee (1889), Ormerod (1904), and Holmes (1905), although Garland and Astley's family (1950) had wasting of the calf muscles and one or two members of the families described by Schut (1950) had wasting elsewhere in the body.

Miss K.K. $\left(V_{3}\right)$ was the first patient seen when she was referred to the Neurological Department at the Middlesex Hospital in 1959 and she was admitted for investigation of the wasting of the small muscles of the hands. The condition had a superficial resemblance to motor neurone disease but this was discounted by the report that other members of her family were similarly affected. A great aunt, III $_{11}$, and aunt, $\mathbf{I V}_{3}$, who were still living, had been admitted in 1912 and 1954 to the National Hospital for Nervous Diseases, Queen Square, and to the London Hospital respectively for the investigation of similar complaints. It was clear that K.K. was suffering from some form of familial neurological disorder.

Thirty-five individuals were examined. These included the siblings of K.K. (with the exception of one elder sister), her mother, her maternal uncles and aunts and their offspring, and her maternal grandfather. In addition, the great aunt who had been admitted to the National Hospital for Nervous Diseases was re-examined and as many of her children and grandchildren were seen as was possible. All were examined in their own homes. 




FIG. 1. Pedigree of the $K$ family.

THE K FAMILY

K.K. (THE PROPOSITA) Miss K.K., aged 20, $\mathrm{V}_{3}$ (her mother is $\left.I V_{1}\right)$, at the age of 16 developed a minor pulp space infection of the right index finger; this was lanced and appeared to recover, but some three months later she found that the finger had become weak and she was unable to type properly, as she could not strike the keys firmly. Her grip also became weak and she found that she was dropping cups. At this time she noticed that the muscles at the back of her right hand had become wasted, particularly between the thumb and index finger. This weakness and wasting gradually progressed to involve all the muscles of her right hand (Figs. 2 and 3). She was admitted for investigation to hospital at the age of 18 in 1959.

She had had no previous illness.

On examination she was an attractive, intelligent girl of short stature. The only abnormality in the cranial nerves was a little weakness of the lower part of her face. In the upper limbs she showed minimal weakness and wasting of the right deltoid and infraspinatus muscles with slight winging of the right scapula. There was also minimal weakness of the extensors of the right wrist with wasting of the dorsal interossei on that side and flattening of the thenar eminence. In the left upper limb the only abnormality was slight flattening of the thenar eminence. Tone and coordination were normal throughout.

In the lower limbs there was a little weakness of hip flexion.

The tendon reflexes were absent in the right arm; they were symmetrically increased in the lower limbs. The right plantar was extensor, the left equivocal.

There was no suggestion of any sensory disturbance in either upper or lower limbs on even the most searching tests, nor was there any indication of cerebellar involvement. There was no nystagmus or dysarthria, and she performed all the tests of cerebellar function quickly and accurately.
Her gait was a little stiff, but this was attributed to the minor pyramidal disturbance in the lower limbs.

Investigations revealed no abnormality in the radiographs of the skull or chest. Radiographs of the spine showed a minor scoliosis, but there were no congenital abnormalities and no cervical ribs. The cerebrospinal fluid had a protein content of $70 \mathrm{mg} . / 100 \mathrm{ml}$. but was otherwise normal in the chemical constituents, serology, and hydrodynamics. The haemoglobin, white blood count, Wassermann reaction, plasma proteins, serum vitamin $\mathrm{B}_{12}$ level, urinary amino-acids, and chromosome constitution were normal.

A myelogram was performed on two occasions and $\stackrel{2}{2}$ found to be normal.

She has been studied on six separate admissions over a period of three years. Apart from some slight increase in the wasting in the affected muscles she has remained well. She has continued working, using an electric typewriter, and has recently married.

The pedigree of Miss K.K. is described below.

$I_{1}$ This man (described by his grandson $\mathrm{III}_{4}$,) one of the older members of the family, was the village smith and lived an active life until the age of 90 . He had the same wasting of the muscle on the back of the right hand between the thumb and index finger (first dorsal interosseus) as had the other members of the family who were similarly affected. This necessitated his gripping the hammer in a curious way, but he never had any difficulty in walking.

$I_{1,2,3}$ (Father was $I_{1}$.) There was no abnormality in this generation.

$I I I_{1,2,3,12,13}$ (Mothers were $\mathrm{II}_{1}$ and $\mathrm{II}_{3}$.) No information is available.

$I I_{5,6,7,8,9,10}$ (Mother was $\mathrm{II}_{2}$.) One sister had died, aged 66, of raised blood pressure. Five sisters are reported to be alive and well.

$\mathrm{III}_{4} \mathrm{Mr}$. B.C., aged 65 (mother was $\mathrm{II}_{2}$ ), was a cooperative man of above-average intelligence.

Examination showed no abnormality in the cranial 


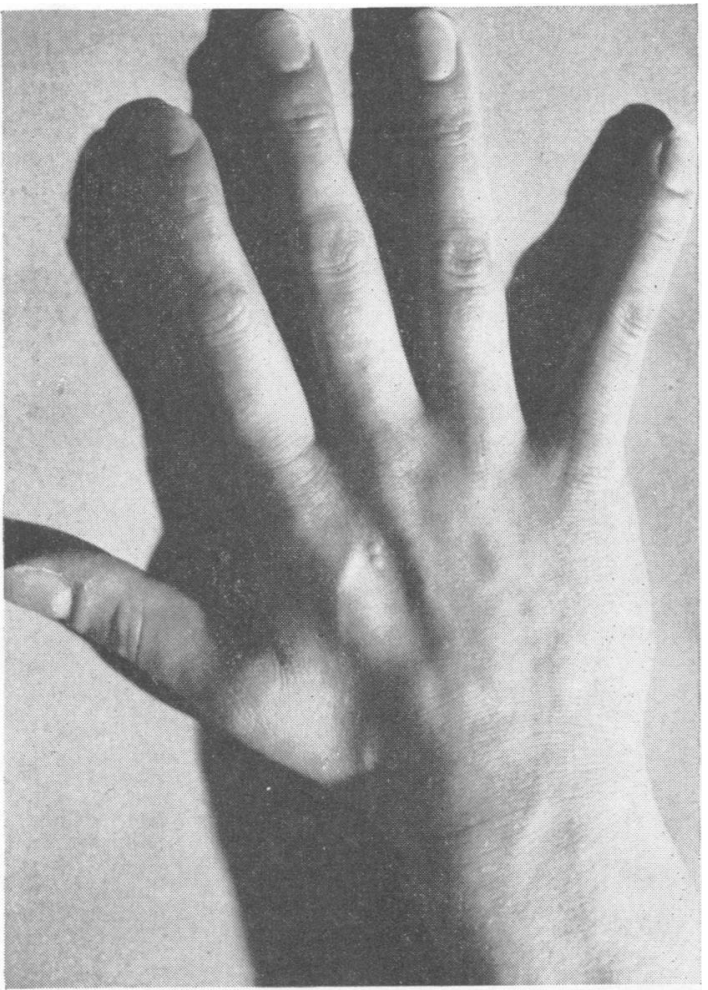

FIG. 2. Wasting of the dorsal interosseous muscles of the right hand of $V_{3}$ in the $K$ family.

nerves. There was no weakness or wasting in the upper limbs apart from the first dorsal interosseous muscle, which was grossly wasted in both hands, and some weakness of the abductor pollicis brevis in the right hand. In the lower limbs he showed marked pes cavus. The reflexes were normal in the upper limbs and pathologically brisk in the lower limbs. The abdominal responses were absent. The plantar responses were equivocal. Sensation was normal. There were no cerebellar signs, his gait was normal. Subsequently, he developed hypertension and 'dizzy turns'.

$I I I_{11}$ Mrs. G., aged 66 (mother was $\mathrm{II}_{2}$ ), had first noticed weakness in her limbs when she was 15 . Her right hand was weak and she was always dropping things. She was admitted at that time to the National Hospital, Queen Square, and her case record has been studied. She was found in 1912 to have wasting of the thenar and hypothenar muscles, and of the interossei on both sides, the right being more affected than the left. She also had slight, but definite wasting and weakness in the muscles of opposition of the thumb, abduction and adduction of the digits, again more marked on the right. The lower limbs appeared to be normal, although they jumped at night. All the reflexes, including the abdominal, were present and the plantars were flexor. There was no sensory disturbance. A radiograph showed a splinter of

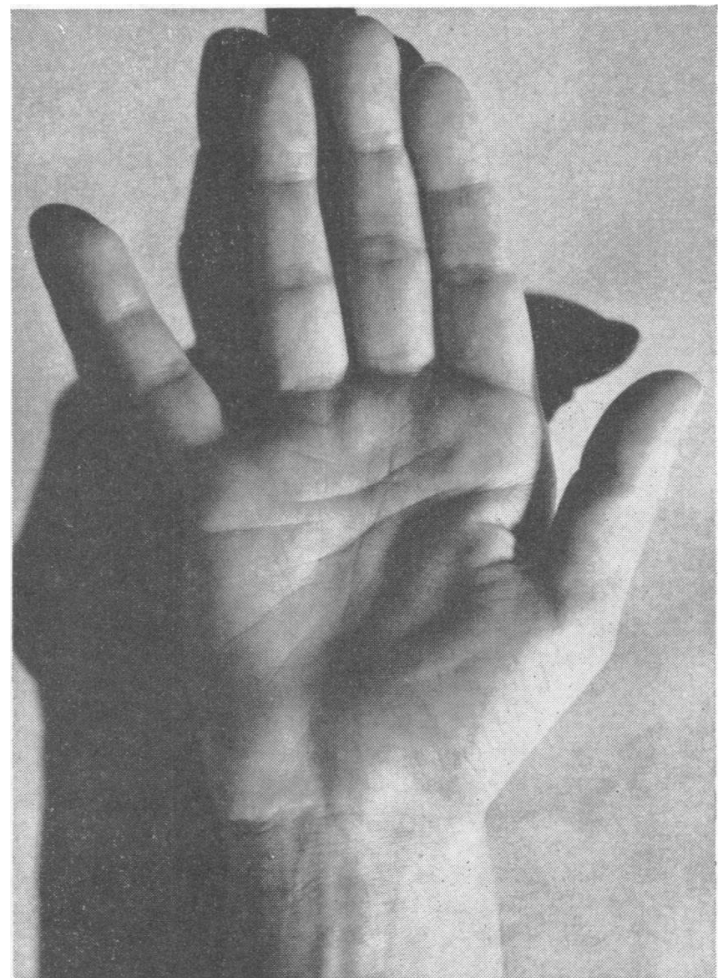

FIG. 3. Wasting of the thenar muscles of the right hand of $V_{3}$ in the $K$ family.

bone in the position of a cervical rib, but this was regarded as inadequate to explain the symptoms. No definite diagnosis was made. She was thought to have either a myopathy or progressive muscular atrophy and was discharged after three months of study.

In the years which elapsed she had a family of five healthy children. The only illness was an operation for peptic ulcer. At present her main complaint was difficulty in using the right thumb so that she was very awkward when managing cups and saucers. She had difficulty in holding her legs still because of cramps, and was awakened at night by nocturnal twitching in her legs. Her walking had always been poor because of stiffness in the legs and deformity of the feet, and she has never walked more than a mile. She had recently become mildly dyspnoeic.

$\mathrm{Her}$ face appeared expressionless although there were no abnormalities in the cranial nerves on formal testing. In the upper limbs she showed marked wasting and weakness of the abductor pollicis brevis on both sides with a lesser degree of weakness and wasting of the interossei. In the lower limbs there was well-marked spasticity and weakness in the hip flexors. All the reflexes were pathologically brisk with extensor plantar responses on both sides. Pin-prick and vibration sense was very slightly impaired in both feet, but her gait appeared normal for short walks. She had a coarse tremor of both 
outstretched hands and a well-developed pes cavus. General examination showed moderate rheumatoid changes in the hands.

There had clearly been little progression in the 50 years since she had been examined at the National Hospital, Queen Square, though more obvious signs of pyramidal damage had appeared.

$I V_{10,11,12,13,14}$ (Mother is III $_{11}$.) Three of Mrs. G's daughters were seen and their children; they all appeared normal on neurological examination.

IV 1 Mrs. K., aged 43 (father is $\mathrm{III}_{4}$ ), reported that she had never been ill, although she had noticed a little weakness of the right thumb and had had difficulty in fastening buttons since childhood. She had also noticed slight weakness and stiffness in her legs.

She was of similar build to her daughter and sister. Examination showed that the cranial nerves were normal. She had some weakness and wasting of both supraspinati, both thenar eminences, and the first dorsal interosseous muscle on the right. In addition, there was some weakness but no wasting of the other interossei on the left.

She had some weakness of the erector spinae and the glutei and she could not lift herself from the couch without using her arms. She had thinning of the distal third of the legs with marked clawing of the feet. There was mild spasticity of the lower limbs. The reflexes of all four limbs were pathologically brisk with bilateral extensor plantar responses. There was no sensory disturbance; there were no cerebellar signs. Her gait was spastic with a superimposed steppage element. General examination was normal.

$I V_{2}$ Mr. G.C., aged 41 (father is $\mathrm{III}_{4}$ ), and his two children (a daughter of 16 and a son aged $13\left(\mathrm{~V}_{13,14}\right)$ ) were quite normal.

$I V_{3}$ Mrs. R.R., aged 39 (father is $\mathrm{III}_{4}$ ), first noticed deformed feet when she was aged 16 and in domestic service. Although she had difficulty in walking, she was able to continue at work. During her first pregnancy, at 19 , she noticed tingling in the hands which disappeared after the delivery, but at the age of 30 she again developed tingling in the right hand. Three years later she was admitted to The London Hospital and found to have wellmarked wasting of the abductor pollicis brevis and opponens on both sides, with some weakness of the interossei, though there was no sensory loss. She had gross weakness in both lower limbs with large, broad feet. The reflexes were all pathologically brisk and she had bilateral extensor plantar responses; the abdominal reflexes were present. A diagnosis of bilateral carpal tunnel syndrome was made and the pyramidal signs were regarded as being caused by a congenital lesion of the pyramidal tracts.

Decompression of the carpal tunnel was performed on the right and at operation the adventitial sheath of the nerve was found to be thickened and the nerve slightly enlarged. Following the operation the tingling in the right hand disappeared but the wasting and weakness were unchanged.

She was admitted to the Middlesex Hospital on 23 September 1960, complaining of tingling in the left hand, particularly in the third digit, and of cramps in the feet with difficulty in walking and standing. The findings were the same as recorded above, except that her gait appeared to be more spastic than was recorded previously and she had a moderate lordosis.

Radiographs of the chest, skull, and wrists were normal; the cervical spine showed degenerative changes and the odontoid peg a congenital abnormality. Blood was normal in all respects, including plasma proteins and Wassermann reaction.

$I V_{4}$ Mr. P.C., aged 37 (father $\mathrm{III}_{4}$ ), was the most severely affected member of the family. He was well as a child and boy, joining the Navy at 18, and was apparently fit on his discharge, resuming his trade as a printer. At about the age of 25 he was observed to have a curious gait; people stopped him in the street and asked him if he had been wounded in the war. His gait had become progressively worse and during the last two years he had been wakened by stiffness and cramps in the night.

The degree of disability did not prevent him running about with his children.

At the same time as the trouble in the legs began, he noticed difficulty in gripping type with his thumb and forefinger, and he found that it was difficult to pick things up because of the weakness in his right thumb. Examination showed that he had a slight asymmetry of the face against the right side. The jaw jerk was pathologically brisk. In the upper limbs there was wasting of the abductor pollicis brevis on the right and of the first dorsal interosseus. There were similar, though less marked, changes in the left. The other upper limb muscles were normal. In the lower limbs there was no wasting, $\mathbb{D}$ but a little weakness on formal testing. The deep reflexes were pathologically increased throughout. The abdominal reflexes were present. He had bilateral patellar and ankle clonus, but the plantar responses were flexor. There were no sensory or cerebellar disturbances. He walked with a spastic gait, dragging the outer edges of his feet.

$V_{20,21}$ Mr. P.C.'s two children were quite normal. Their father is $\mathrm{IV}_{4}$.

The following are the children of Mrs. K., the siblings of Miss K.K. (mother is IV $_{1}$ ).

$V_{1}$ Mr. P.K., aged 23, had marked pes cavus with wasting of the distal third of the lower limbs. He had full power but slight increase of tone. The reflexes were pathologically brisk in the lower limbs with bilateral extensor plantar responses. There were no other abnormalities on general or neurological examination.

$V_{2}$ Miss $\mathrm{K}$. was not seen; she was married and not reported to be affected.

$V_{3}$ Miss K.K. is described above.

$V_{4}$ Mr. D.K., aged 19, showed severe pes cavus with clawing of the toes. The lower limb reflexes were pathologically brisk and he had an equivocal plantar response on the right; the response was flexor on the left. The abdominal reflexes were absent.

$V_{5}, V_{6}$, and $V_{7}$ Mr. A.K., aged 16, Mr. R.K., aged $13 \frac{1}{2}$, and Miss J.K., aged 10, were quite normal.

$V_{8}$ Miss R.K., aged 9, had a harsh systolic murmur which could be heard over the whole of the praecordium.

$V_{9} \quad$ R.K., aged 7, one of a pair of non-identical twins, had bilateral extensor plantar responses.

$V_{10}$ G.K., aged 7, the other member of the pair of non- 
identical twins, had no abnormality on general or neurological examination.

$V_{11}$ and $V_{12}$ Miss D.K., aged 4, and Miss H.K., aged 9 months, were quite normal.

$V_{15-19}$ These are the children of Mrs. R. (mother is IV $\mathrm{V}_{13}$ ).

P.R., $\left(\mathrm{V}_{15}\right)$ aged 20 , was a bright young man with marked pes cavus and an equivocal right plantar response.

M.R., $\left(\mathrm{V}_{16}\right)$ aged $17 \frac{1}{2}$, was an intelligent boy just taking his General Certificate Examination. He had marked pes cavus. The plantar responses were flexor.

C.R., $\left(\mathrm{V}_{17}\right)$ aged 15, was an intelligent boy. He walked with a curious gait, that had been commented on, as though he dragged his feet and could not use them. He had weakness of the glutei, evertors, and invertors of the feet, and a marked pes cavus. The reflexes were pathologically brisk and the plantar responses were flexor.

A.R. $\left(\mathrm{V}_{18}\right)$, aged 10, had pes cavus but no spasticity.

D.R. $\left(\mathrm{V}_{19}\right)$, aged 2 , had no abnormality.

Attention was drawn to the existence of another family similarly affected when $\mathrm{Mr}$. H.A.( $\left(\mathrm{II}_{3}\right)$ was admitted to the Middlesex Hospital for a cataract operation and observed to have severe bilateral wasting of the small muscles of his hands. He was referred to the Neurological Department for investigation of this complaint. When he disclosed that other members of his family were similarly affected, the opportunity was taken to investigate his two children $\left(\mathrm{III}_{1}\right.$ and $\left.\mathrm{III}_{2}\right)$, four grandchildren $\left(\mathrm{IV}_{1,2,3,4}\right)$, and his sister $\left(\mathrm{II}_{4}\right)$ either at their homes or in the Out-patient Department.

Figure 4 is the pedigree of the A family.

\section{THE A FAMILY}

$\mathrm{II}_{3}$ (THE PROPOSITUS) Mr. H.A., aged 65 (father was $I_{1}$ ), was admitted to the Middlesex Hospital for a cataract operation at the age of 65 . At that time he was found to have bilateral wasting of all the small muscles of the hands and he reported difficulty in picking things up since the age of 16 . This had become progressively worse. It did not prevent his serving in the 1914-18 war, after which he had worked as a bus inspector until his retirement at the age of 65 .

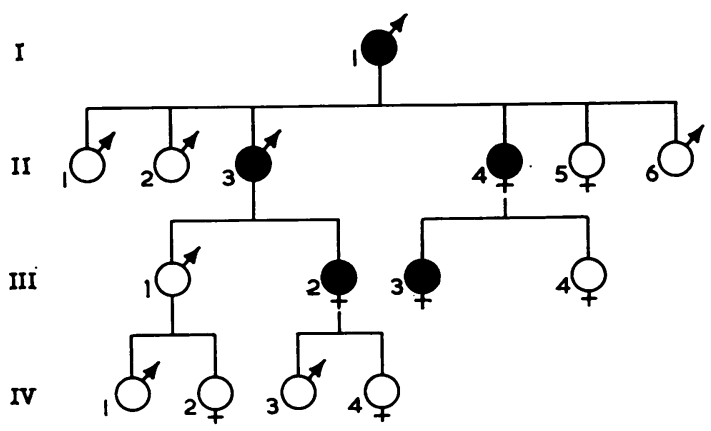

FIG. 4. Pedigree of the A family.
The wasting and weakness was of such severity that he could not grip a pencil in the normal manner, but instead held it between his index and middle fingers. $\mathrm{He}$ denied any disability in the legs.

In the past he had suffered from attacks of lower abdominal pain associated with diarrhoea; he had had a rectal polyp removed and he also had hypertension.

He was a heavily built, plethoric man of limited intelligence. The cranial nerves were normal. There was no skeletal abnormality. He had some fasciculation of the left deltoid, thinning of both brachioradialis, and marked wasting of the thenar and hypothenar muscles on both sides. There was weakness of the long flexors of the fingers and the wrists with complete loss of power in the interosseous and thenar muscles. There was minimal weakness of the hip flexors. In the upper limbs the reflexes were depressed. In the lower limbs they were considerably increased with bilateral extensor plantar responses. The abdominal responses could not be obtained. There was loss of vibration sense to the knees with no other sensory abnormality. He had high-arched feet. There were no cerebellar signs. His gait was normal. General examination was normal apart from a blood pressure of $180 / 130 \mathrm{~mm} . \mathrm{Hg}$.

Radiographs showed that there were degenerative

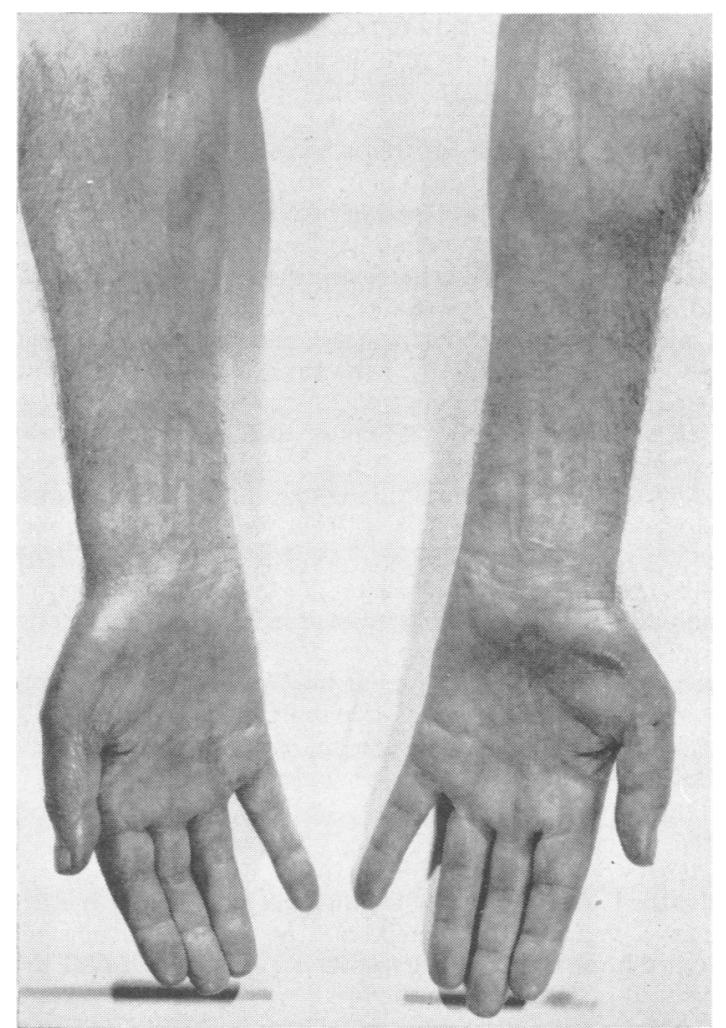

FIG. 5. Wasting of the thenar muscles of $\mathrm{II}_{3}$ in the $A$ family. 
changes in the cervical spine; the skull was normal, the heart was a little enlarged. An electrocardiogram was suggestive of ischaemia. Haemoglobin, white blood count, blood urea, blood sugar, and serum electrolytes were normal. The Wassermann reaction was negative.

II 4 Mrs. B. (sister of Mr. A.), aged 62 (father was $I_{1}$ ), first noticed trouble with her hands when she was aged 30 . She found that she could not grip a needle between her thumb and index fingers; the weakness had slowly progressed over the years and when she was seen she had difficulty in doing up buttons and managing her housework. During the last two or three years, she experienced increasing difficulty in walking as her toes kept catching on the kerbs, causing her to fall on two or three occasions.

She was of the same large build as her brother and niece. There was severe wasting in the thenar, hypothenar, and interosseous muscle in both hands with hardly any power. Her toes were clawed, but there was no pes cavus. All the deep reflexes were increased, except for the left ankle jerk which was depressed. The right plantar response was extensor, the left was equivocal; vibration sense was impaired to the knees.

General examination was normal. She has subsequently had a stroke.

Because of contradictory statements by $\mathrm{Mr}$. A. $\left(\mathrm{II}_{3}\right)$ and Mrs. B. $\left(\mathrm{II}_{4}\right)$ it was impossible to determine how many brothers and sisters there were in the family. The numbers fluctuated between six and twelve. They were in agreement on the following points:

Their father $\left(I_{1}\right)$ was the only member of the family apart from themselves and their children to show the same complaint. He developed wasting of the hands at the age of 30 and died of a stroke at the age of 66 . During his later years he was troubled with stiff knees and he attended University College Hospital. There he was diagnosed as suffering from osteoarthritis, which was confirmed by $x$-ray studies. This has been verified. Unfortunately, no other medical examinations were made.

One elder brother $\left(\mathrm{II}_{2}\right)$, who was not affected, died of a stroke at the age of 66 .

No other brothers or sisters or their offspring 'showed the family complaint'.

III $_{3}$ and III $_{4}$ The two daughters of Mrs. B. (mother is $\mathrm{II}_{4}$ ) were not seen. Mrs. B. said that one of them was much more severely affected than Mrs. B. herself. This daughter had developed wasting of the hands at an earlier age and in addition had a twisted back. She was the only individual who, despite repeated requests, declined to be seen either at her home or at hospital.

The other daughter was said to be normal.

Both daughters had been married for several years, but had not been able to conceive any children.

$\mathrm{III}_{2}$ Mrs. B., aged 45, daughter of Mr. A. (father is $\mathrm{II}_{3}$ ), at the age of 20 found that she was unable to pick up pins and other small objects, due to weakness and wasting of the hands. This disability had progressed to such a degree that she could not sew or hold buttons and had the greatest difficulty with her housework. She had noticed no disability in the legs.

She was of a similar heavy build to her father and aunt. There was gross bilateral wasting of all the small muscles of both hands with hardly any residual power at all. She

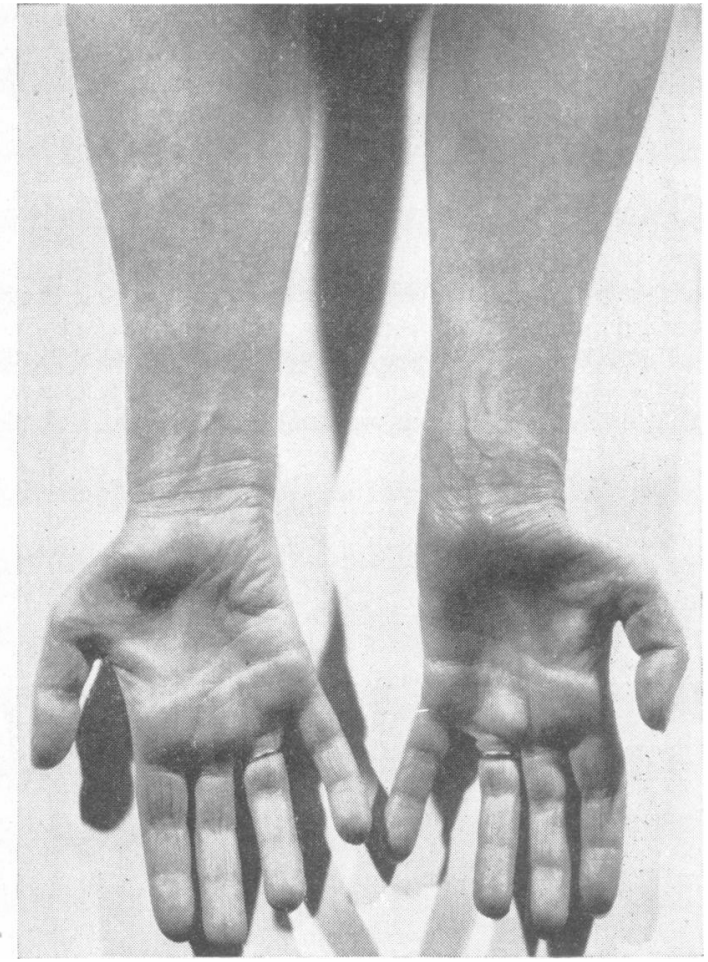

FIG. 6. Gross wasting of the thenar muscles and the whole palm of the hand of $\mathrm{III}_{2}$ in the A family.

had slight weakness of the hip flexors. The deep reflexes were increased throughout. The abdominal reflexes were present; the plantars were flexor. There was no sensory or cerebellar disturbance. Her gait was normal. General examination was normal. In the past she had been seen as an out-patient at the National Hospital for Nervous Diseases, Queen Square, and was thought to be suffering from a form of peroneal muscular atrophy.

$I V_{3,4}$ M.B. and C.B., the children of Mrs. B. (mother is $\mathrm{III}_{2}$ ), a boy aged 17 and a girl aged 15 , were both seen and found to be normal.

$\mathrm{III}_{1} \mathrm{Mr}$. H.J.A., aged 43, son of Mr. A. (father is $\mathrm{II}_{3}$ ), was a healthy, fit man with no abnormality on general or neurological examination. He had two children.

$I V_{1,2}$ D.A. and J.A., children of Mr. H.J.A. (father is $\left.\mathrm{III}_{1}\right)$, the eldest, D.A., was a slender boy of 10 years. There was no abnormality on general or neurological examination, apart from the fact that he had high-arched feet and it was difficult to be certain of the response of the right plantar. The youngest child, J.A., was a stout girl, full of energy, aged 3 years, weighing 4 stone 8 pounds. She was rather an unruly child and it was difficult to carry out a full examination, but there was no wasting of the hands and the plantar responses were flexor; she appeared to walk quite normally.

The clinical picture presented by these two families 
is so similar that they are described together and any points of difference noted. Every endeavour has been made to avoid interpreting minor variations from normal as abnormalities or defects belonging to this clinical syndrome. Three members of the $\mathrm{K}$ family and one member of the A family have been admitted to hospital at different times and examined independently by neurologists who have substantiated the findings. One member had attended the Outpatient Department, the other members of the families were seen at their homes. The full clinical picture, which was present in nine members of these two families, could be diagnosed easily once the situation was appreciated. The presenting complaint was severe wasting of the small muscles of the hands as shown by difficulty in sewing, holding a cup, doing up buttons, and other fine movements. The wasting appeared between the ages of 15 and 30 and it usually did not progress after a few years, or progressed extremely slowly. Some members of the $\mathbf{K}$ family noticed a little weakness of the shoulder muscles.

No member of either family volunteered a complaint of difficulty with the legs and if they noticed anything amiss in their lower limbs it was insufficient to cause them to visit their doctor, whereas doctors had been consulted because of trouble with the hands. On direct questioning four members of the $\mathrm{K}$ family and one of the A family stated that they had had some trouble with their legs and that this took the form of stiffness, cramps, and tripping over the kerb or small projections when walking. Examinations showed severe global wasting of the small muscles of the hand, the abductor, the opponens, the flexor pollicis, and first dorsal interosseus. In some cases, the long flexors of the wrist were affected. The wasting and weakness were often of a degree sufficient to cause complete loss of power in these muscles. Occasionally the wasting spread to involve the shoulder girdle. In the lower limbs when marked spasticity was present there was weakness of the hip flexors and the evertors of the feet.

The reflexes were brisk throughout except in the cases of A.K. and Mr. A. in whom they were depressed in the upper limbs. Sensation was normal, apart from three individuals who had impaired vibration sense in the lower limbs, but as these patients were over 62 when seen, this finding may not be significant. There were no cerebellar signs or involuntary movements. The weakness of the glutei gave an excessive lordosis and this, combined with the spasticity in the lower limbs and some deformity of the feet, gave a combined steppage and spastic gait. In the $\mathbf{K}$ family, in the fifth generation, there were individuals who showed marked pes cavus and extensor plantar responses; in two members there was also marked wasting in the lower third of the calves, but this was not associated with any wasting of the hands. This was not seen in the A family.

\section{DISCUSSION}

The two pedigrees show clearly that the disorder was transmitted in each family on a dominant basis from an affected parent to some offspring. When allowance is made for the small numbers involved it was not possible to demonstrate any difference in the severity of the disorder between the two sexes. There were minor differences in the distribution and the severity of the disorder between the two families. In the A family the disorder was mainly localized in the hands, whereas in the $\mathrm{K}$ family, the manifestations were more widespread, and in the fifth generation a more diverse picture was seen. This variation in the fifth generation may have been due to the natural evolution of the disorder. This is not uncommon and was seen in the younger generations of Bickerstaff's family (1950). There was no suggestion that these two families or the family described by Gee (1889) were related to each other. The A family originated in Kent, the $\mathrm{K}$ family had been living in a small village in Bedfordshire for many generations, and Gee's family were natives of the East End of London.

The age of onset was difficult to determine since the disorder was insidious in its progress. But in two cases, K.K.( $\left(\mathrm{V}_{3}\right)$ and Mrs. G.(III $)_{11}$ accurate information was available and the disorder appeared before the age of 17. All the other affected members were seen many years after the onset of the disorder and as a consequence, their early recollections were not very accurate.

Taking all these observations and recollections into consideration, it would seem to indicate that the disorder appeared in late adolescence rather than in childhood and this observation is in keeping with Bell and Carmichael's (1939) findings in the dominant form of transmission in the familial ataxias. There were five men and seven women affected by the disorder. There was no obvious difference between the sexes in the age of onset or in the severity of the signs and symptoms. In the 11 affected individuals who have married fertility has not been impaired.

Ten have children, and there is no apparent difference in the number of offspring to the affected men and women; five affected males have had 17 children and seven affected females have had 26 children.

Only one affected woman, who has not been seen, has failed to have children.

The disorder pursued a different course in the two families. In the $\mathrm{K}$ family the wasting of the hands. never became so severe that the individual could not 
dress or carry on with his job, but the pyramidal disturbance in the lower limbs did give rise to cramps and a stiff gait after many years. In the $A$ family the wasting of the hands was more severe and disabling; several affected individuals had the greatest difficulty in dressing and writing, but none complained of any cramps in the legs.

In no case has the disorder progressed to complete disability. Only two affected members have died up till now, at the ages of 90 and 66 . The latter individual died of a stroke. It is unlikely that in either case life was shortened by the disorder. This is contrary to the experience of previous investigators like Schut (1950) and Refsum (1961) who have recorded that in the families they studied the condition was progressive, the affected individuals being confined to their beds for their declining years and dying of bronchopneumonia.

The most striking feature of this disorder was the wasting of the muscles. This varied between the families in its age of onset, degree, and distribution.

In the A family it came on later, was more sharply localized, more severe and disabling than in the $\mathrm{K}$ family. There was complete atrophy of the thenar and hypothenar muscles. In $\mathrm{Mr}$. $\mathrm{A}\left(\mathrm{II}_{3}\right)$ and his daughter it had spread strikingly to involve the distal third of the forearms, and the appearance was so similar to that of peroneal muscular atrophy that this diagnosis was entertained when the daughter attended the Out-patient Department at the National Hospital, Queen Square.

In the $\mathrm{K}$ family, although the age of onset was earlier and the manifestations more widespread, the wasting was much less severe, there only being some hollowing of the first dorsal interosseous muscle and of the thenar pad. The exception was the proposita, Miss K.K. $\left(\mathrm{V}_{\mathbf{3}}\right)$, in whom the wasting had spread outside the hands and there was some thinning of the shoulder muscles.

Her elder brother, who had no wasting of the hands, had marked distal thinning of the calves. This brother also had pyramidal signs in the lower limbs.

The distribution of the wasting would appear to link the disorder with Freidreich's ataxia and peroneal muscular atrophy, but the pyramidal signs in the lower limbs in the affected individuals and their presence in the siblings of A.K. would appear to relate the condition to familial spastic pareplegia.

In the family described by Gee (1889), comprising a father and two affected daughters, the father appeared to have a similar clinical picture, that is, marked wasting of the hands which did not prevent him working, with a rather more severe pyramidal disturbance in the lower limbs.

The manifestations in the case of his two daughters were rather different in that they had little localized wasting of the hands and marked spasticity of all the limbs. It is possible that in time wasting might have appeared in their hands; alternatively, it is not uncommon for a hereditary disorder to show variable manifestations in different generations.

The families described by Ormerod (1904) and Holmes (1905) had a similar distribution of wasting, but the disorders were more severe and progressive. This is hardly surprising since in Gee's family the disorder was transmitted on a dominant basis as in the $K$ and $A$ families, whereas in Ormerod's and Holmes' cases it was on a recessive basis, and it has been shown by Bell and Carmichael (1939) that when similar clinical pictures are produced by either dominant or recessive inheritance, that caused by the recessive inheritance is more severe than that caused by the dominant inheritance because there are two abnormal genes present, whereas in a dominant inheritance there is a normal gene to modify the abnormal one.

Unfortunately, there have been few post-mortem reports on cases of familial spastic paraplegia and none were performed in the small group of cases described by Gee (1889), Ormerod (1904), and Holmes (1905) where amyotrophy of the hands was a prominent feature so the causation of this wasting is unknown.

The pyramidal disturbance in the lower limbs was of only a minor nature since no member of either family complained of weakness or unsteadiness though when questioned directly, several members of the $\mathrm{K}$ family said they had difficulty in walking and had cramps in the legs at night.

Difficulty was found in interpreting the significance of the finding of minimal evidence of pyramidal damage and severe pes cavus in the younger members of the $\mathrm{K}$ family. There are several possible explanations. It may be that these were early manifestations of the disorder, and that in time wasting of the hands would appear. This seemed unlikely because $V_{1}$, who was three years older than the proposita $V_{3}$, showed extensor plantar responses, claw feet, and distal thinning of the legs yet he had no sign of any disorder in the hands. An alternative explanation is that there were independent genes for each component of the disorder, one gene governing the inheritance of the wasted hands and one gene the pyramidal disturbance, and that these could be inherited independently. This appears to be the more likely explanation.

The minor sensory disturbances exhibited in two members of the $\mathrm{A}$ family, $\mathrm{II}_{3}$ and $\mathrm{II}_{4}$, and one member of the $\mathrm{K}$ family, $\mathrm{III}_{11}$, are not unusual in familial spastic paraplegia. Similar observations were made by Bell and Carmichael (1939), Sjögren 
(1943), and Bickerstaff (1950) in individuals in families that they described. This is hardly surprising, since Strümpell $(1880,1886,1904)$ in the first necropsies performed in this condition, found degeneration of the posterior columns, but on the other hand, it should be pointed out that all the individuals in the $\mathrm{A}$ and $\mathrm{K}$ families who showed this sensory impairment were over 60 at the time of the observation and at least one was known to have degenerative changes in the cervical spine.

A negative observation of considerable interest was that no member of either family showed any evidence of ataxia.

Several of the previous families have shown a combined picture of cerebellar and pyramidal signs. Bell and Carmichael (1939) could not find any satisfactory reason either clinically or genetically for distinguishing between familial spastic paraplegia (that is pyramidal signs in the lower limbs alone) and spastic ataxia (pyramidal signs accompanied by cerebellar signs); they regarded them as one disorder. Schut (1950) found in the few members of his large family who presented with pyramidal signs that in time they developed cerebellar signs. These views are contrary to those advanced by Strümpell (1880) and to the findings of Garland and Astley (1950) and Refsum (1954, 1961). In their families, no cerebellar signs developed despite long observation.

The majority of the individuals were seen in their homes so little could be attempted in the way of laboratory investigations. Linkage studies were carried out and are the subject of a separate communication. In the three individuals who were admitted to hospital the investigations were of a nature to exclude such disorders affecting the spinal cord as syphilis, diabetes, and pernicious anaemia, and radiographs of the skull, foramen magnum, and cervical spine were taken. In one of the most severely affected individuals, $\mathrm{V}_{3}$, the plasma proteins, urinary amino acids, and chromosome constitution were normal.

The relationship of the disorder in these two families to other familial disorders of the nervous system must await further pathological and biochemical information about the nature of the disease process. But the benign prognosis, the similarity of the manifestation to the family described by Gee (1889), and the occurrence of individuals in the $\mathrm{K}$ family whose only abnormality was a pyramidal disturbance in the lower limbs suggest that this is a variety of familial spastic paraplegia. Although superficially the disorder bears a resemblance to motor neurone disease, it may be distinguished by the lack of progression of the disorder and its clear inheritance on a dominant basis.
SUMMARY

Two unrelated British families suffering from wasting of the hands associated with spastic paraplegia are described. The condition was transmitted as a dominant trait and 12 individuals were affected, nine of whom were examined.

Wasting of the small hand muscles was severe and was the presenting and chief disability and appeared between the ages of 15 and 30 . The pyramidal disturbance in the lower limbs was relatively minor.

The disorder carries a benign prognosis, does not shorten life, or lead to great disability.

The mode of inheritance and the clinical features of the disorder are reviewed.

I wish to record my gratitude for the encouragement and advice that I received from Dr. Michael Kremer. The patients were admitted and investigated under his care and without his kindness and stimulating advice this study would not have been completed.

I would like to thank Professor Lionel Penrose, who throughout the investigation helped and advised me on the genetic aspects of the work. He generously permitted the chromosome studies to be carried out in the Galton Laboratory by Miss Ruth Marshall.

I wish to thank Mr. Ainslie and Mr. Goldsmith for referring the propositus, Mr. A., and Mr. Northfield and Lord Brain for allowing me to quote from their original notes on Mrs. R. when she attended the London Hospital.

I would like to thank Dr. Julia Bell and Dr. A. Carmichael for discussing these families with me.

I wish to thank Mr. Frank Beck for translating the German papers which I have quoted and Dr. Russell Doggart for his helpful advice and criticism.

I am also grateful to Mr. Turney for the preparation of the photographs, and to Mr. Lee for the preparation of the diagrams.

\section{REFERENCES}

Bell, J., and Carmichael, E. A. (1939). On heriditary ataxia and spastic paraplegia. In The Treasury of Human Inheritance, edited by R. A. Fisher, vol. 4, pt. 3. Univerity Press, Cambridge.

Bickerstaff, E. R. (1950). Hereditary spastic paraplegia. J. Neurol. Neurosurg. Psychiat., 13, 134-145.

Dick, A. P., and Stevenson, C. J. (1953). Hereditary spastic paraplegia; report of a family with associated extrapyramidal signs. Lancet, 1, 921-923.

Ferguson, F. R., and Critchley, Macdonald (1929). A clinical study of an heredo-familial disease resembling disseminated sclerosis. Brain, 52, 203-225.

Garland, H. G., and Astley, C. E. (1950). Hereditary spastic paraplegia with amyotrophy and pes cavus. J. Neurol. Neurosurg. Psychiat., 13, 130-133.

Gee, S. (1889). Hereditary infantile spastic paraplegia. St Bart. Hosp. Rep., 25, 81-83.

Holmes, G. (1905). Family spastic paralysis associated with amyotrophy. Rev. Neurol. Psychiat., 3, 256-263.

Jones, E. (1907). Eight cases of hereditary spastic paraplegia. Ibid., 5, 98-106.

Landau, W. M., and Gitt, J. J. (1951). Hereditary spastic paraplegia and hereditary ataxia. Arch. Neurol. Psychiat. (Chic.), 66, 346-354. 
Manson, J. S. (1920). Hereditary spastic paraplegia with ataxia and mental defect. Brit. med. J., 2, 477.

Mason, V. R., and Rienhoff, W. F. (1920). Hereditary spastic paraplegia. Bull. Johns Hopk. Hosp., 31, 215-217.

Matson, G. A., Schut, J. W., and Swanson, J. (1961). Linkage studies in hereditary ataxia. Ann. hum. Genet., 25, 7-23.

Newmark, L. (1893). A contribution to the study of the family form of spastic paraplegia. Amer. J. med. Sci., 105, 432-440.

Ogilvie, G. (1908). Hereditary spastic paralysis. Proc. roy. Soc. Med., 1, pt. 2, Neurological section, pp. 91-92.

Ormerod, J. A. (1904). An unusual form of family paralysis. Lancet, 1 , 17-18.

Paskind, H. A., and Stone, T. T. (1933). Familial spastic paralysis. Arch. Neurol. Psychiat. (Chic.), 30, 481-500.

Philip, R. W. (1886). Primary spastic paralysis and pseudo-hypertrophic paralysis in different members of the same family, with probable heredity in both. Brain, 8, 520-527.

Punton, J. (1909). Hereditary spastic paraplegia. Report of seven cases in two families. J. nerv. ment. Dis., 36, 588-600.

Refsum, S. (1961). Some genetic aspects of neurological diseases. In Disorders of the Developing Nervous System, edited by S. W. Fields and M. M. Desmond, pp. 5-22. Thomas, Springfield, Illinois.

- , and Skillicorn, S. A. (1954). Amyotrophic familial spastic paraplegia. Neurology (Minneap.), 4, 40-47.

Rhein, J. H. W. (1916) Family spastic paralysis J. nerv. ment. Dis., 44, 115-144, 224-242.

Roe, P. F. (1963). Hereditary spastic paraplegia. J. Neurol. Neurosurg. Psychiat., 26, 516-519.

Schut, J. W. (1950). Hereditary ataxia; clinical study through six generations. Arch. Neurol. Psychiat. (Chic.), 63, 535-568.
- (1951). Hereditary ataxia. A survey of certain clinical, pathologic and genetic features with linkage data on five additional hereditary factors. Amer. J. hum. Genet., 3, 93-110.

- (1954). The hereditary ataxsia. In Genetics and the Inheritance of Integrated Neurological and Psychiatric Patterns, pp. 293-324. Edited by D. Hooker and C. Hare. (Res. Publ. Ass. nerv. ment. Dis., 33).

Schwarz, G. A. (1952). Hereditary (familial) spastic paraplegia Arch. Neurol. Psychiat. (Chic.), 68, 655-682.

Sjögren, T. (1943). Klinische und erbbiologische Untersuchengen über die Heredoataxien, Acta Psychiat. (Kbh.), suppl. 27.

Strümpell, A. (1880). Beiträge zur Pathologie des Rückenmarks. Arch. Psychiat. Nervenkr., 10, 676-717.

- (1886). Ueber eine bestimmte Form der primären combinirten Systemerkrankung des Rückenmarks. Ibid., 17, 217-238.

- (1904). Die primäre Seitenstrang-sklerose. Dtsch. Z. Nervenheilk., 27, 291-339.

Tooth, H. H. (1891). Hereditary spastic paraplegia. St Bart. Hosp. Rep., 27, 7-14.

Tyrer, J. H., and Sutherland, J. M. (1961). The primary spino-cerebellar atrophies and their associated defects, with a study of the foot deformity. Brain, 84, 289-300.

Williams, G. H. (1918). Family spastic paralysis. J. nerv. ment. Dis., 47, 427-433.

Worster-Drought, C., Hill, T. R., and McMenemey, W. H. (1933) Familial presenile dementia with spastic paralysis. J. Neurol. Psychopath., 14, 27-34.

—, Greenfield, J. G., and McMenemey, W. H. (1940). A form of familial presenile dementia with spastic paralysis. Brain, 63, 237-254.

spastic paralysis. lbid., 67, 38-43. 